\title{
The Immune System's Moderating Response to Inflammation Relieves Autistic Behavior: Response to Peter Good
}

\author{
Marcel Kinsbourne
}

Received: 5 January 2011 / Accepted: 6 January 2011 / Published online: 18 January 2011

(C) Springer Science+Business Media, LLC 2011

Authors Helt, Kelley, Boorstein, Pandey, and Fein, asked authors Kinsbourne and Herbert to respond to the Good letter because of their expertise in this area. Following is Dr. Kinsbourne's response.

Curran et al. (2007) confirmed that children with autism behave less aberrantly when they are febrile due to infections, a phenomenon that might offer insight into the cause and treatment of autistic symptoms. Good (2011) attributes the improvement to an increase in cerebral blood flow. Some brain regions related to autistic symptoms are indeed underperfused (Ohnishi et al. 2000). However, because regional cerebral blood flow is proportionate to metabolic need, diminished perfusion reflects diminished metabolism rather than cause it. Evidence is lacking that fever increases the perfusion of these regions, or that they would function better if it did. Indeed, Curran et al. (2007) found no relationship between degree of fever and degree of improvement.

Fever is the presenting symptom of inflammatory reactions to a pathogen. Absent inflammation, heat stress does not improve behavior in autism (Miles 2010, cited by Good). Therefore, the benefits do not accrue from the rising temperature as such. I suggest that they derive from the immune system's efforts to limit the inflammatory reaction.

The febrile inflammatory response to pathogens is mediated by proinflammatory cytokines, notably IL-1 beta and TNF-alpha (Mackowiak 1998) and promoted by the sympathetic nervous system. In excess, these cytokines would be toxic. The proinflammatory cytokine response is rapidly curtailed by IL-1ra, a specific IL-1 antagonist, and

\section{Kinsbourne $(\triangle)$}

Department of Psychology, New School,

80 Fifth Avenue, \#704,

New York City, NY 10011, USA

e-mail: KinsbouM@newschool.edu by anti-inflammatory cytokines, such as IL-10, TNFbinding protein and transforming growth factor-b (TGF-b) (Czura and Tracey 2005). Moreover, the inflammatory reaction with its sympathetic activation is buffered by the vagal cholinergic anti-inflammatory system (CAIS) (Tracey 2007; Thayer 2009).

The inflammatory reflex of the vagus nerve prevents excessive release of cytokines from macrophages. When the CAIS of mice was inactivated, the cytokine response to endotoxin was excessive (Borovikova et al. 2000). Electrical vagal stimulation is used to treat inflammatory diseases, including depression, which features neuroinflammation (Pucak et al. 2007). Vagal stimulation also increases heart rate variability, as autonomic tone veers from sympathetic toward parasympathetic dominance.

In controlling inflammation and sympathetic predominance, the CAIS may lower arousal level. Much autistic behavior appears to be a compensatory reaction to chronic pathologically heightened arousal (Kinsbourne 2011). Vargas et al. (2005) discovered neuroinflammation in people with autism, both in vivo and at autopsy. An outpouring of cytokines from activated microglia, the CNS counterparts of macrophages, involves the excessive release of glutamate, the preponderant excitatory neurotransmitter, increasing the brain activation toward hyperarousal. By subduing neuroinflammation (Nizri et al. 2009), the CAIS would downregulate arousal and enable adaptive behavior to emerge.

Sympathetic hyperarousal in autism is also well documented. By fostering parasympathetic (vagal) predominance, the CAIS might ameliorate the fearful sensory rejection and urge toward isolation and inward shift of attention that characterizes the autistic state (Kinsbourne 2011).

That autistic behavior can improve during fever demonstrates that it is not necessarily fixed but can constitute a reaction to potentially remediable factors. If the suggested 
mechanism for the improvement is validated, stimulating the vagus nerve to energize the CAIS might offer relief for autistic symptoms.

\section{References}

Borovikova, L. V., Ivanova, S., Zangh, M., Yang, H., Botchikina, G. I., Watkins, L. R., et al. (2000). Vagus nerve stimulation attenuates the systemic inflammatory response to endotoxin. Nature, 405, 458-462.

Curran, L. K., Newschaffer, C. J., Lee, L.-C., Crawford, S. O., Johnson, M. V., \& Zimmerman, A. W. (2007). Behaviors associated with fever in children with autism spectrum disorders. Pediatrics, 120, 1386-1392.

Czura, C., \& Tracey, K. J. (2005). Autonomic neural regulation of immunity. Journal of Internal Medicine, 257, 156-166.

Good, P. (2011). Does fever relieve autistic behavior by improving brain blood flow? Neuropsychology Review. doi:10.1007/s11065011-9157-y.

Kinsbourne, M. (2011). Repetitive movements and arousal. In D. Fein (Ed.), Neuropsychology of autism (pp. 367-394). Oxford: Oxford University Press.
Mackowiak, P. A. (1998). Concepts of fever. Archives of Internal Medicine, 158, 1870-1881.

Nizri, E., Irony-Tur-Sinai, M., Lory, O., Orr-Urtreger, A., Lavi, E., \& Brenner, T. (2009). Activation of the cholinergic antiinflammatory system by nicotine attenuates neuroinflammation via suppression of Th1 and Th 17 responses. Journal of Immunology, 183, 6681-6688.

Ohnishi, T., Matsuda, H., Hashimoto, T., Kunihiro, T., Nishikawa, N., Uema, T., et al. (2000). Abnormal regional cerebral blood flow in childhood autism. Brain, 123, 1838-1844.

Pucak, M. L., Carroll, K. A. L., Kerr, D. A., \& Kaplin, A. I. (2007). Neuropsychiatric manifestations of depression in multiple sclerosis: neuroinflammatory, neuroendocrine and neurotrophic mechanisms in the pathogenesis of immunemediated depression. Dialogues in Clinical Neuroscience, 9, $125-139$.

Thayer, J. F. (2009). Vagal tone and the inflammatory reflex. Cleveland Clinic Journal of Medicine, 76(Supp12), 23-26.

Tracey, K. J. (2007). Physiology and immunology of the cholinergic anti-inflammatory pathway. Journal of Clinical Investigation, 117, 289-296.

Vargas, D. L., Nascimbene, C., Krishnan, C., Zimmerman, A. W., \& Pardo, C. A. (2005). Neuroglial activation and neuroinflammation in the brains of patients with autism. Annals of Neurology, $57,67-81$. 